\title{
Menière's Disease and Disorders of the Carbohydrate Metabolism Involving the Inner Ear
}

\author{
Pedro L. Mangabeira Albernaz ${ }^{10}$ \\ ${ }^{1}$ Department of Otolaryngology, Hospital Albert Einstein, São Paulo, \\ SP, Brazil \\ Int Arch Otorhinolaryngol 2019;23:218-220.
}

\begin{abstract}
Address for correspondence Pedro L. Mangabeira Albernaz, MD, PhD, Departmento de Otorrinolaringologia, Hospital Albert Einstein, Av. Albert Einstein, 627, Sala 117, São Paulo, SP, 05652-000, Brazil (e-mail: plmalbernaz@gmail.com).
\end{abstract}

\begin{abstract}
Keywords

- menière's disease

- carbohydrate metabolism

- endolymphatic hydrops

Introduction Menière's disease was described in 1861, but there are still uncertainties regarding its pathophysiology and treatment. Endolymphatic hydrops is recognized as a fundamental pathological characteristic of the disease, as a result of an inadequate absorption of the endolymph. A milder type of endolymphatic hydrops results from an altered chemical composition of the endolymph, due to disorders of the carbohydrate metabolism.

Objective To describe the association of both types of hydrops in patients with Menière disease.

Methods This was a retrospective study of 98 patients with Menière's disease, 62 of whom also presented disorders of the carbohydrate metabolism, and 5 patients with delayed endolymphatic hydrops, 2 of whom also presented disorders of the carbohydrate metabolism.

Results The follow-up of these patients showed that the correction of the metabolic disorders may help in the clinical treatment of Menière's disease and of delayed endolymphatic hydrops, but this does not happen in the more severe types of the diseases. Conclusion Patients with Menière's disease may present simultaneous disorders of the carbohydrate metabolism, affecting the inner ear. The correction of these disorders helps the clinical treatment but does not preclude the progression of the more severe cases of Menière disease.
\end{abstract}

\section{Introduction}

Menière's disease was described in 1861, but there are still many uncertainties regarding its pathophysiology and treatment.

The presence of endolymphatic hydrops in Menière's disease has been confirmed by many authors, in many temporal bones, although it may also be present in some other inner ear diseases, such as tertiary syphilis and Mondini dysplasia. ${ }^{1,2}$

The endolymphatic hydrops associated with Menière's disease is probably linked to a faulty absorption of the endolymph. It has been experimentally developed in laboratory

Dedro L. Mangabeira Albernaz's ORCID is https://orcid.org/00000003-0067-9095.

received

May 31, 2018

accepted

August 14, 2018

published online

February 15, 2019 animals-guinea pigs, cats and rabbits-by obstructing the endolymphatic duct or destroying the endolymphatic sac. ${ }^{2}$

A totally different type of endolymphatic hydrops is related to carbohydrate metabolism disorder, in which there are changes in the chemical composition and in the density of the endolymph. ${ }^{3}$

It should be noted that in Menière's disease, the chemical composition of the endolymph remains unchanged, while in metabolic hydrops the amount of sodium is increased, and the amount of potassium is decreased. The hydrops is caused by water intake to the endolymphatic space to adjust the osmotic pressure, as a consequence of a faulty operation of the sodium-potassium pump of the stria vascularis. ${ }^{3,4}$

These two types of hydrops can occur simultaneously, since their pathophysiological mechanisms are totally independent.

Copyright @ 2019 by Thieme Revinter

Publicações Ltda, Rio de Janeiro, Brazil
License terms

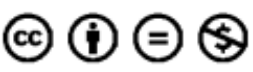


The objective of the present study is to evaluate the occurrence of carbohydrate metabolism disorders in patients with Menière's disease. It also includes cases of delayed endolymphatic hydrops, which can be considered as a variation of Menière's disease.

\section{Methods}

The present study comprised 98 patients with Menière's disease and 5 patients with delayed endolymphatic hydrops, seen in a private clinic for a 10-year period (from 2008 to 2017). The diagnosis of Menière's disease was established according to the proposals of the Bárány Society ${ }^{5}$; all of the patients with delayed endolymphatic hydrops had a history of profound unilateral hearing loss during childhood.

There were 59 women and 39 men in the Menière's disease group; there were 4 women and 1 man in the delayed endolymphatic hydrops group.

During the same time period, 257 patients were found to have disorders of the carbohydrate metabolism involving the inner ear. This diagnosis was established by clinical history, feeding habits, familial history of diabetes, and glucose tolerance tests with simultaneous insulin titration, according to Kraft. $^{6}$ There were 135 patients with hyperinsulinemia (Kraft curve types II, IIIA and IIIB), and 122 patients with brush border membrane disease (Kraft curve type $\mathrm{V}$ plus lactose intolerance). The lactose intolerance was confirmed by either a lactose tolerance test or a molecular blood test. ${ }^{3}$

The present research was approved by the Ethics Committee of the Hospital Israelita Albert Einstein (CAAE: 36936314.8.0000.0071).

\section{Results}

Among the 257 patients with metabolic disorders, there were 62 that presented with Menière's disease, and 2 patients that had delayed endolymphatic hydrops ( $\mathbf{- T a b l e ~} \mathbf{1}$ ).

Of the 98 patients in the Menière's disease group, 20 (20.4\%) presented with an incapacitating disease that did not respond to clinical treatment and were submitted to an endolymphatic sac operation (-Table 2 ).

Of the five patients with delayed endolymphatic hydrops, only two had associated metabolic disorder, both with hyperinsulinemia. One of them was socially and professionally incapacitated and required a labyrinthectomy.

Table 1 Relations between Menière's disease and carbohydrate metabolic disorders

\begin{tabular}{|l|l|}
\hline Patients with Menière's disease \\
\hline Without metabolic disorders & 36 \\
\hline With hyperinsulinemia & 33 \\
\hline With brush border membrane disease & 24 \\
\hline With diabetes mellitus II & 5 \\
\hline TOTAL & 98 \\
\hline
\end{tabular}

Table 2 Relations between the operated patients and metabolic disorders

\begin{tabular}{|l|l|}
\hline \multicolumn{2}{|l|}{ Patients submitted to endolymphatic sac surgery } \\
\hline Without metabolic disorders & 4 \\
\hline With hyperinsulinemia & 8 \\
\hline With brush border membrane disease & 7 \\
\hline With diabetes mellitus II & 1 \\
\hline TOTAL & 20 \\
\hline
\end{tabular}

\section{Discussion}

The many attempts to determine the etiology of Menière's disease have not achieved significant facts. There is much evidence that it may be a genetic disease; about one in three patients with Menière's disease has a first-degree relative that also has the disease. It has also been suggested that it may be linked to developmental problems of the inner ear, or to autoimmune disorders. It seems clear that a variation of Menière's disease, delayed endolymphatic hydrops, is of viral origin, linked mainly to the virus of epidemic parotiditis. ${ }^{7}$ Therefore, other cases may also have a viral origin. For the majority of the cases, the etiology cannot be established; these are usually labeled idiopathic Menière's disease.

Disorders of the carbohydrate metabolism are very common. ${ }^{6}$ Hyperinsulinemia is frequently associated with insulin resistance or high consumption of small molecule sugars, most often in patients with a familial tendency for diabetes. It may also occur in patients with diabetes mellitus type II, who may present periods of hypoglycemia caused by their medications. $^{3}$ Brush border membrane disease is linked to an inadequate or non-existent production of lactase and its frequency varies in different areas of the world. ${ }^{8}$

It would seem that disorders of the carbohydrate metabolism could be a possible etiology for Menière's disease. The follow-up of these patients, however, showed that although they have cochlear and vestibular symptoms, they do not evolve to typical Menière's disease.

The association of Menière's disease and carbohydrate metabolism disorders is common, supporting the concept that the two kinds of endolymphatic hydrops may occur simultaneously, since they derive from independent pathophysiological mechanisms.

It must be taken into consideration, however, that Menière's disease is quite variable; there are benign cases, with infrequent episodes of vertigo, and there are severely incapacitating cases.

In many patients with a combination of Menière's disease and inner ear metabolic disorders, the correction of the metabolic problems definitely helped in their clinical treatment.

The correction of the metabolic disorders, however, did not preclude the evolution of the more severe forms of Menière's disease. Of the 98 patients in the Menière's disease group, 20 (20.4\%) were submitted to endolymphatic sac surgery. This high percentage is most probably related to 
the fact that this is a biased sample; many patients were referred by other physicians after the clinical treatment failed. The estimated guess is that only $\sim 5 \%$ of the patients need surgical treatment. It should be noted that several of these operated patients had metabolic disorders, the correction of which did not halter the progression of the disease.

Although the patients with delayed endolymphatic hydrops usually have severe vertiginous symptoms, some of them respond to clinical treatment. The sample of the present study is too small to conclude if the treatment of the simultaneous metabolic disorder will be of help to these patients.

\section{Conclusion}

Patients with Menière's disease may present simultaneous disorders of the carbohydrate metabolism affecting the inner ear. The correction of these disorders helps the clinical treatment of these patients. It does not preclude, however, the progression of the more severe cases of the disease.

\section{References}

1 Hallpike CS, Cairns H. Observations on the Pathology of Ménière's Syndrome: (Section of Otology). Proc R Soc Med 1938;31(11): 1317-1336

2 Merchans SN, Nadol JB Jr. Schuknecht Pathology of the Ear. 3rd ed. Shelton, CT: People's Medical Publishing House; 2010

3 Albernaz PL. Hearing Loss, Dizziness, and Carbohydrate Metabolism. Int Arch Otorhinolaryngol 2016;20(03):261-270

4 Mangabeira Albernaz PL, Fukuda Y. Glucose, insulin and inner ear pathology. Acta Otolaryngol 1984;97(5-6):496-501

5 Lopez-EscamezJA, Carey J, Chung WH, et al; Classification Committee of the Barany Society; Japan Society for Equilibrium Research; European Academy of Otology and Neurotology (EAONO); Equilibrium Committee of the American Academy of Otolaryngology-Head and Neck Surgery (AAO-HNS); Korean Balance Society. Diagnostic criteria for Menière's disease. J Vestib Res 2015;25(01):1-7 Doi: 10.3233/VES-150549

6 Kraft JR. Diabetes Epidemic and You. Trafford Publishing; 2008

7 Albernaz PL. Unusual cases of delayed endolymphatic hydrops. Acta Otolaryngol 2007;127(04):355-359

8 Mangabeira-Albernaz PL, Miszputen SJ. Vertigem e enzimas digestivas. In: Zuma e Maia FC, Mangabeira-Albernaz PL, Carmona S. Otoneurologia Atual. Rio de Janeiro: Revinter; 2014:365-379 